\title{
The Observation of Superparamagnetic Behavior in Molecular Nanowires
}

\author{
Shi Wang, ${ }^{\dagger}$ Jing-Lin Zuo, ${ }^{*}{ }^{\dagger}$ Song Gao, ${ }^{\ddagger}$ You Song, ${ }^{\dagger}$ Hong-Cai \\ Zhou, ${ }^{\S}$ Yuan-Zhu Zhang ${ }^{\ddagger}$ and Xiao-Zeng You ${ }^{*} \dagger$
}

\section{Supporting materials}

\section{Experimental Section}

$\left(\mathrm{Bu}_{4} \mathrm{~N}\right)\left[(\mathrm{Tp}) \mathrm{Fe}(\mathrm{CN})_{3}\right]$ was prepared by a modified literature method. ${ }^{1}$ Cyanides are toxic and should be handled with great caution!

$\left[(\mathrm{Tp})_{2} \mathrm{Fe}^{\mathrm{III}}{ }_{2}(\mathrm{CN})_{6} \mathrm{Cu}\left(\mathrm{CH}_{3} \mathrm{OH}\right) \cdot 2 \mathrm{CH}_{3} \mathrm{OH}\right]_{\mathrm{n}}$ 2: A solution of $\left(\mathrm{Bu}_{4} \mathrm{~N}\right)\left[(\mathrm{Tp}) \mathrm{Fe}(\mathrm{CN})_{3}\right](118$ $\mathrm{mg}, 0.2 \mathrm{mmol})$ in methanol $(2 \mathrm{ml})$ was layered carefully on top of a solution of $\mathrm{Cu}\left(\mathrm{NO}_{3}\right)_{2} \cdot 6 \mathrm{H}_{2} \mathrm{O}(30 \mathrm{mg}, 0.1 \mathrm{mmol})$ in water $(2 \mathrm{ml})$. Brown needlelike crystals of 2 were obtained after two weeks $(80 \%)$. IR: $v=2129,2177 \mathrm{~cm}^{-1}\left(v_{\mathrm{CN}}\right)$; Anal. calcd for $\mathrm{C}_{25} \mathrm{H}_{24} \mathrm{~B}_{2} \mathrm{CuFe}_{2} \mathrm{~N}_{18} \mathrm{O} \cdot \mathrm{CH}_{3} \mathrm{OH}: \mathrm{C}, 38.02 ; \mathrm{H}, 3.44 ; \mathrm{N}$ 30.69. Found: C, 37.86; H 3.53; N, 30.21 .

(1) Lescouëzec, R.; Vaissermann, J.; Lloret, F.; Julve, M.; Verdaguer, M. Inorg. Chem. 2002, 41, 5943.

\section{Magnetic Measurements}

Magnetic susceptibility measurements for sample 2 were obtained with the use of a Quantum Design MPMS-XL7 SQUID magnetometer at temperature ranging from $1.8-300 \mathrm{~K}$. The dc measurements were collected from -70 to $70 \mathrm{kOe}$. Data were corrected for the diamagnetic contribution calculated from Pascal constants. The ac measurements were performed at various frequencies from 0.1 to $1000 \mathrm{~Hz}$ with the ac field amplitude of 5 Oe and no dc field applied. The second harmonic ac magnetic susceptibility was measured in an Oxford Instruments MagLab2000 system. 

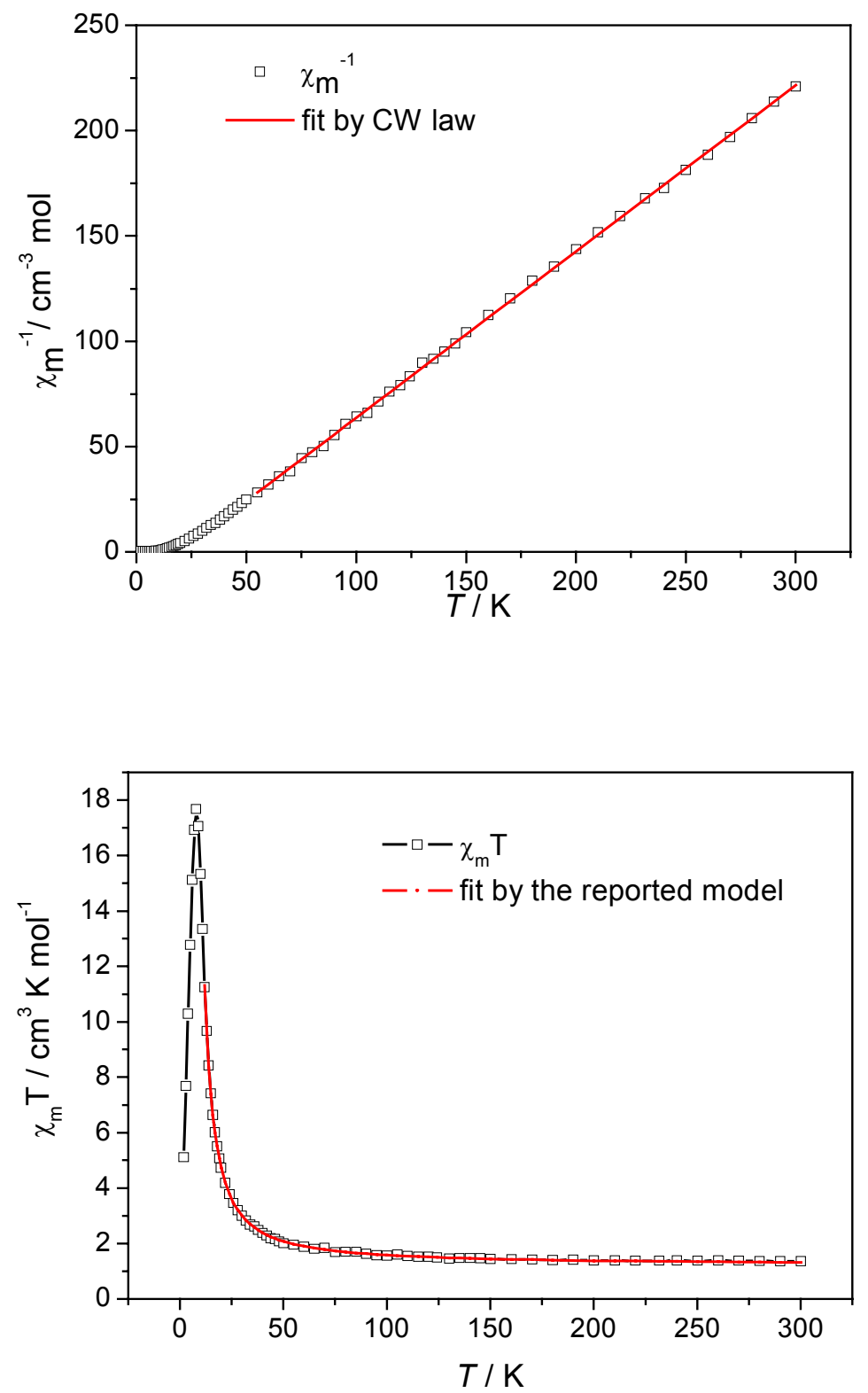

Figure S1. Temperature dependence of $\chi_{\mathrm{m}}{ }^{-1}$ and $\chi_{\mathrm{m}} T$ for 2 .

The reported formula is:

$\chi=N g^{2} \mu_{\mathrm{B}}^{2} / 2 k T\left\{E\left[4 \exp \left(K^{+}\right)+\cosh \left(K^{+}\right)+1\right]-8 \cosh \left(K^{+}\right)-\cosh \left(K^{-}\right)\right\} /\left\{E\left[E-2 \cosh \left(K^{+}\right)-2\right]\right\}$ (where $E=2\left[\cosh \left(K^{+}\right)+\cosh \left(K^{-}\right)+2\right], K^{+}=\left(J_{1}+J_{2}\right) / 2 k T, K^{-}=\left(J_{1}-J_{2}\right) / 2 k T, J_{1}$ is magnetic interaction within the trimer and $J_{2}$ is magnetic interaction between adjacent trimers)

Drillon, M.; Coronado, E.; Belaiche, M.; Carlin, R. L. J. Appl. Phys. 1988, 63, 3551. 


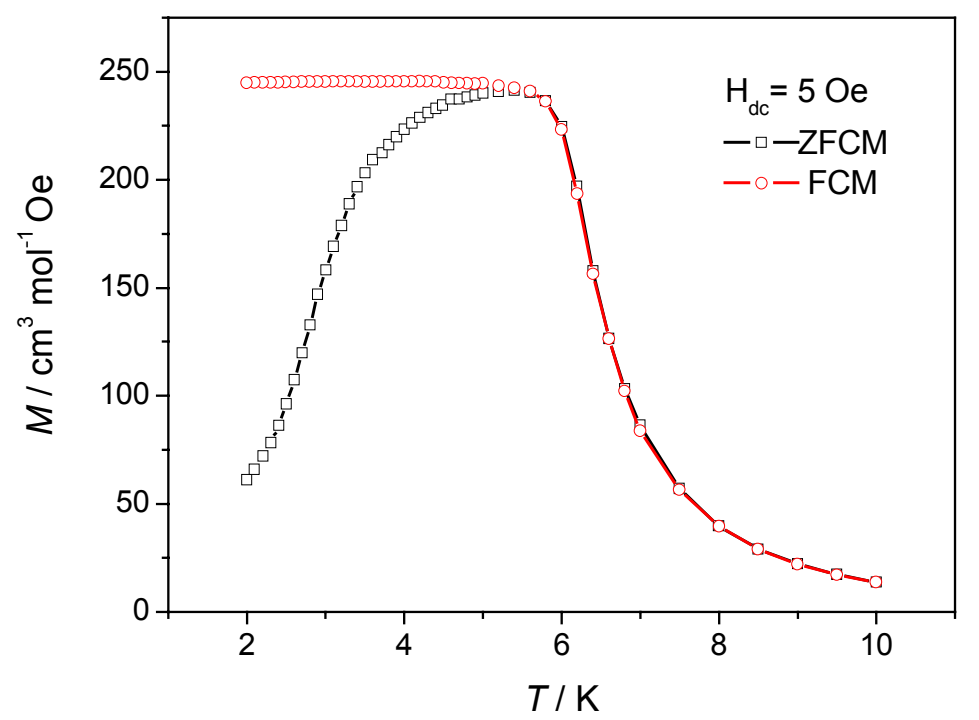

Figure S2. Temperature dependence of the zero-field cooled magnetization (ZFCM) and field-cooled magnetization (FCM) in a field of 5 Oe for 2.

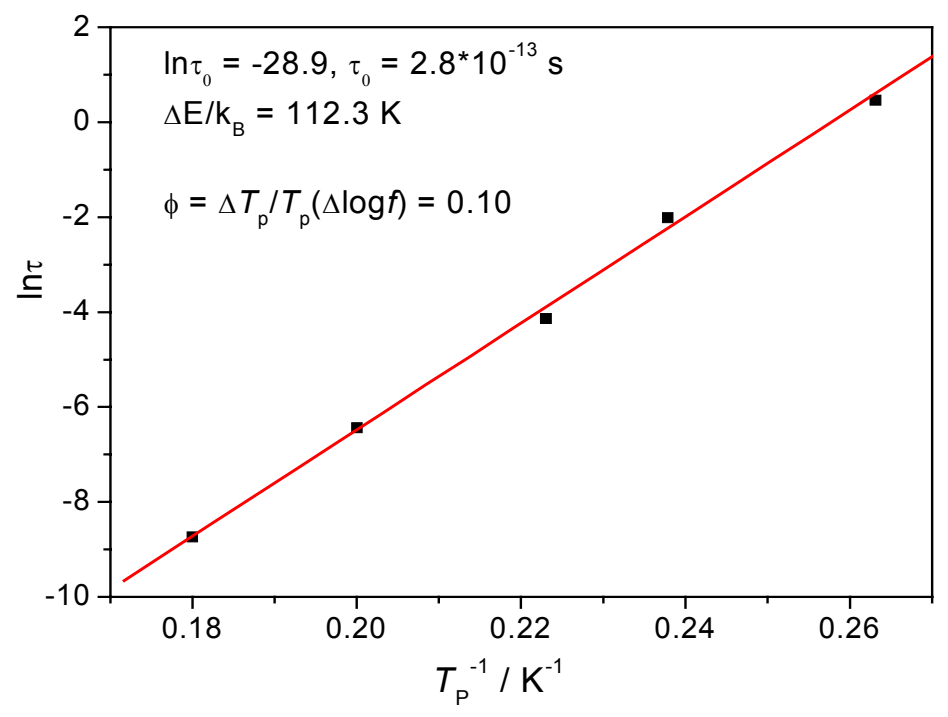

Figure S3. Frequency dependence of $\mathbf{2}$ was fitted by Arrhenius law $\tau=$ $\tau_{0} \exp \left(-\Delta E / \mathrm{k}_{\mathrm{B}} T\right)$. 


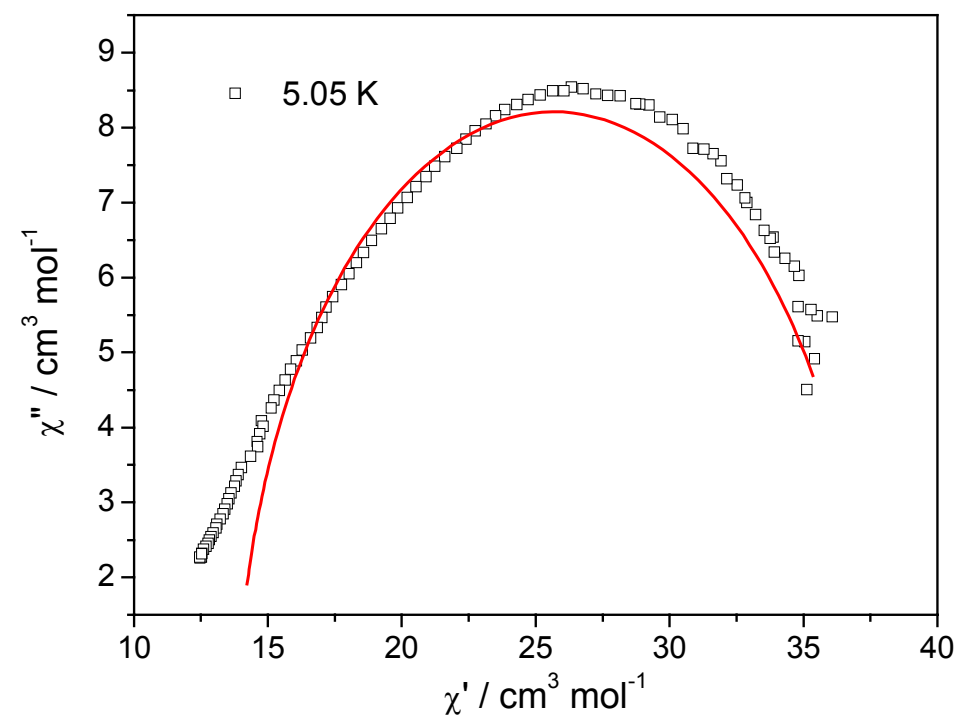

Figure S4. Cole-Cole plot of 2 at $5.05 \mathrm{~K}$ at zero applied dc field. The solid lines are least-squares fitting of the data to a distribution of single relaxation processes with a generalized Debye model, giving parameter values: $\chi_{\mathrm{S}}=13.5 \mathrm{~cm}^{3} \mathrm{~mol}^{-1}, \chi_{\mathrm{T}}=36.5 \mathrm{~cm}^{3}$ $\mathrm{mol}^{-1}, \tau=0.0014 \mathrm{~s}, \alpha=0.52$.

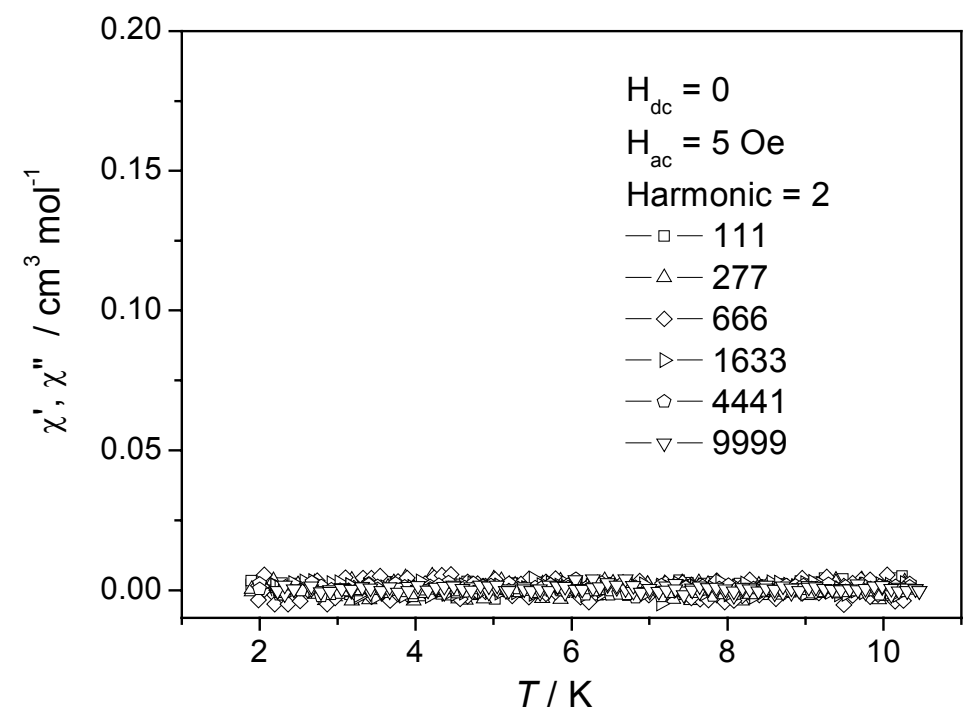

Figure S5. Temperature dependence of the real and imaginary components of the second harmonic $a c$ susceptibility for $\mathbf{2}$ in zero applied static field with an oscillating field 5 Oe in frequency of $111-9999 \mathrm{~Hz}$. 


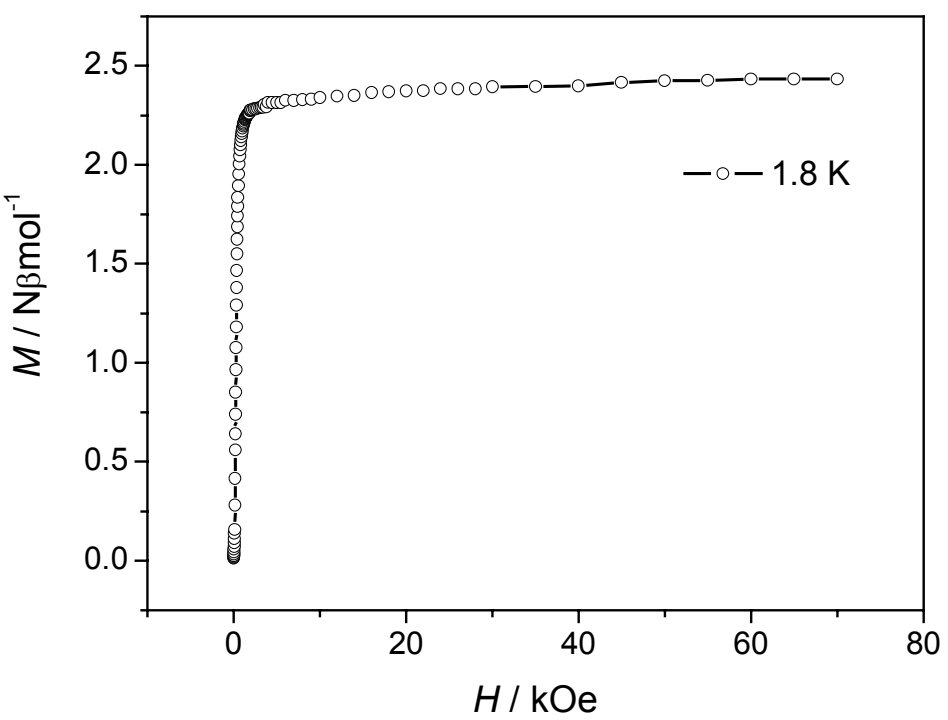

Figure S6. Field dependence of the magnetization for 2 at $1.8 \mathrm{~K}$. 